\title{
Physiotherapy Education: Global trends, perspectives and future direction
}

\author{
Oyeyemi, A.Y. \\ Department of Physiotherapy, College of Medical Sciences, University of Maiduguri, Maiduguri, Nigeria; and \\ Hunter College Graduate Center, City University of New York, New York, NY 10016 USA. \\ Correspondence \\ Dr. A.Y. Oyeyemi, Department of Physiotherapy, College of Medical Sciences, University of Maiduguri, \\ Maiduguri, Nigeria; E-mail: adeoyeyemi@aol.com
}

\begin{abstract}
SUMMARY
The advances in technology and the recent transformation in global communication, which are increasingly reducing the spatial limitation in education, have influenced perspectives on how education is delivered. This paper presents a global trend in higher education with particular reference to education and training in physiotherapy and other health professions. It outlines the variables and models of education, the competencies in allied health and medical education and also discusses the relevance and resource needs to internationalize physiotherapy education in Nigeria. Instituting transnational education in Nigeria will require improvements in electronic pedagogical infrastructure and learning resources and curriculum enhancements, and may also require contributions from Nigerians in the Diaspora.
\end{abstract}

KEY WORDS: Physiotherapy education, future direction, international education, transnational education

\section{INTRODUCTION}

The emergence of physiotherapy as a distinct health discipline is historically tied to injuries suffered by veterans during the World Wars (Backlay, 1995). Subsequent decades after the wars witnessed a rapid improvement in sanitation techniques, inroads through aging research, and progress in general and medical technologies, which resulted in an increased elderly population and the frequency of elective surgeries worldwide. These advances have led to changes in perspectives on health and the related quality of life, increased the relevance and scope of physiotherapy, and warranted a redefinition of this discipline.

Recently, factors driving changes in the curriculum content and delivery method of medical and allied health education were identified as the globalization of health care delivery (Harden, 2006), development of common and unique vocabularies in each health discipline, and the need for outcome-based education and training standardization. (Schwarz and Wojtczak, 2002; Harden, 2002; WCPT, 2009). Other factors contributory to changes in health professional training, and higher education in general, are staff development (Harden, 2006), competitiveness
(Knight, 2005) and the commercialization of education (Coleman, 2003).

It is a general belief that the recent improvement in global communication and internet facilities have effectively reduced the spatial limitation placed on teaching, and new learning technologies and pedagogical advances have increased the repertoire and armamentarium of resources on teaching and learning. Therefore, it can be argued that a good training institution is one that maximally utilizes internet facilities and electronic pedagogical resources for the benefit of the trainees and the society.

An awareness of emerging trends on the delivery of education broadens the horizon of professionals and educators, and enriches their perspectives on effective didactic and clinical teaching practices and options, and also provides insights into the future of professional training in a global village. The apparent emphasis on medical education in this paper is not so much for its sake as much as it is that in no other health discipline than medicine and its specialties have substantial empirical data on training and education been reported. This paper outlines the variables and models of health professional 
education and articulates the relevance and the resource need for enhanced physiotherapy training in Nigeria.

\section{EVOLUTION OF INTERNATIONAL EDUCATION}

Educational exchanges across national boundaries have been in existence since medieval times in Europe (Harden, 2002). Early in the $19^{\text {th }}$ century, universities collaborated across nations, and craftsmen worked all around Europe for some years early in their careers before they eventually settled in one country (Teichler, 2003). Prior to independence, the nationals of many African countries received their university and professional training in the United Kingdom, France and USA.. Today, many professionals from African countries pursue graduate medical and health professional education in the developed countries in Europe and North America.

Harden (2006) surmised that the student, the teacher and the curriculum are the tripod upon which learning rests and that the interrelationship between these variables defines models of education. In this scheme (figure 1), an insular model of education involves a local stuent, a local teacher and a local curriculum (bottom left quadrant). This model, or a version of it involving collaboration between programmes within a national boundary, is what obtains in many training programmes in virtually all developing countries, and existed in the developed countries until the later part of the last century.

\begin{tabular}{|c|c|c|c|}
\cline { 2 - 3 } Teacher & $\begin{array}{c}\text { International Teacher } \\
\text { Visiting Lecturer }\end{array}$ & $\begin{array}{c}\text { Transnational Student } \\
\text { A Vision of the Future }\end{array}$ \\
\cline { 2 - 4 } & & $\begin{array}{c}\text { Virtual Teacher } \\
\text { (Movement of Teachers) }\end{array}$ & \\
\cline { 2 - 4 } & & $\begin{array}{c}\text { Local Student } \\
\text { (Insular Model) }\end{array}$ & $\begin{array}{c}\text { International Student } \\
\text { Exchange Programs } \\
\text { (Movement of Students) }\end{array}$ \\
\hline \multicolumn{2}{|c|}{ Local } & International \\
\hline \multicolumn{2}{|c|}{ Student } \\
\hline
\end{tabular}

Figure 1. Internationalization of physiotherapy education viewed from the perspectives of movement of teachers and students involves teachers and students that are local or international. There is an observable but gradual shift from a curriculum taught by local teachers to local students, to a model where there is greater mobility and either international sudents or international teachers. The future lies in a transnational curriculum with international teachers and international students (Culled from Harden, R.M. International Medical Education and Future Directions: Global Perspectives. Academic Medicine 2006, 81 (12): S22-S28).
An insular training model or its intranational collaborative version offers perspectives to medical and health professional education and practice in the context of a nation or country. It is almost universally-accepted that, given the factors driving changes in education described above, this model is no longer a preferred mode of professional training (Harden, 2006). Consequently, a collaborative model of education involving cooperation between programmes in different countries has evolved.

One version of a collaborative model involves student exchanges between countries. In an elaborate version of the collaborative model involving programmes in two different countries, students complete a substantial part of their training abroad (Broadhead and Muula, 2002), while in a conservative version, students travels overseas to receive some educational exposure as electives (Bottom right quadrant of figure 1). Collaborative education from the teachers' perspectives involves the movement of teachers and their contributions through text books and other learning resources to other countries (Top left quadrant of figure 1).

In the recent wave of the international expansion of universities, a curriculum such as transitional Doctor of Physical Therapy developed in one country is exported and used in another country (NYIT, 2007, Touro College, 2008). One version of a collaborative education involves local students and local curricula, with shared local and international teachers. Collaborative international education now considered the norm in Europe, is characterized by libraries across universities in Europe, Asia, and North America networked through broadband internet access (Harden, 2006).

Collaborative international education that emphasizes the movement of variables is fraught with drawbacks. Developing countries are often shortchanged in many instances when they send students for training in the developed countries (Muulan, 2005; Aluwihare 2005; Broadhead and Muula, 2002). Only a few foreign students return to their homeland after completing their studies, and these students are neither more internationallyminded nor friendlier to their host country (Teichler, 2003). It is a general belief that procuring the services of foreign teachers may be unrealistic; cost perspectives and importing foreign curricula can even be construed as recolonization by the developing countries.

The goal of professional education is to produce practitioners with competency in both the technical and cultural aspects of practice. Technical competence is the ability to perform a specific task in a given situation, while cultural competence involves the nuances and 
understanding that enable a practitioner to communicate effectively with patients and other health professionals, and to select the culturally-appropriate diagnosis and treatment. An international collaborative educational model that de-emphasizes the movement of variables and therefore eliminates drawbacks as noted above is the preferred education and is the future direction.

\section{TRANSNATIONAL EDUCATION}

In transnational education, internationalization is integrated and embedded within a curriculum and involves collaboration between a number of schools in different countries. In this approach, the study of physiotherapy is exemplified in the global context rather than in the context of a single country. Although local needs are considered in educating individual students, the overall focus of the curriculum is on globally-accepted outcomes, competencybased learning experiences and planned real or entirely virtual international experiences.

In transnational education, physiotherapy education is removed from its spatial context and the common problems facing health care professionals internationally, as well as locally, to become part of the learners' experience. The goal of international education is not to produce an 'undifferentiated' internationalist professional. Transnational education addresses both the technical and cultural competence of professional training and supplants the erroneous notions that cultural competence is not easily evaluable, measurable or transportable.

A generic or global cultural competence can be achieved through the acquisition of a comprehensive set of core skills derived from international relations, crosscultural psychology, and intercultural communication that are applicable to health professional education (Harden, 2006). Global cultural competency training focuses on the policy and social factors, as well as the individual considerations that can alleviate suffering and enhance the health and well-being of patients in a global society (Huang, 2003; Harden and Hart, 2002).

Cultural competence in transnational education encompasses interpersonal skills that are valuable in encounters with patients from diverse cultural and social backgrounds. It emphasizes developing the ability to gather health-related information and analyzing it critically, instead of memorizing previously reported socio-cultural findings. It also facilitates a true understanding of health attitudes and behaviours in the practice of physiotherapy in different cultures. Global cultural competence could be easily adapted and utilized in different situations and cultural settings.
In the United States, entry level physiotherapy training received by immigrants in their homeland is often presumed, albeit erroneously, to be international education. Cultural competency has also been misapplied to a curriculum emphasizing reliance on lists of ethnocentric characteristics or single factor explanations, rather than patient-centered inquiry or multidimensional analysis including ethno-cultural determinants and transitions in class, geographic locations and identity (Salafsky et al., 2005). International education so misconstrued and cultural competence so misapplied do not constitute a transnational education.

Internationalized education is now an integral part of professional medical education and is also gaining popularity in physiotherapy education in the developed countries (Harden, 2006; Touro College, 2008). Recent developments and innovations such as Peripatetic Electronic Teachers, and experience with International Virtual Medical Schools demonstrated great possibilities and potentials of transnational education. Today, the use of webinar and electronic blackboards are common delivery modes especially in distance education in all fields.

A learning object approach to instructional designs that utilizes small chunks of learning materials such as diagrams, clinical photograph or a short instructional sequence to make up a learning program, (Harden and Hart 2002) virtual practice and a curriculum map, are gaining popularity. A model that utilizes patients covering key areas of practice has been used as a basis for a medical curriculum in presenting problems in problem-based learning or as a resource for interactive exercises or case studies to illustrate principles and concepts (Smith et al, 2007) and can also be used in physiotherapy education.

\section{DISCUSSION}

Today, an ideal provider of health services is one that practices based on evidence, and consumers' perception of how a physiotherapist's skills can influence outcome. Anecdotal reports of Nigerian physiotherapists practicing in the diaspora shows that patients' confidence and perception of physiotherapists skills can also be influenced by whether the clinician is foreign-trained or not. Recently, an increasing number of Nigerians have been seeking medical services abroad and physical therapy often needs to be continued upon return. Internationalization of training programmes in Nigeria could improve cross country inter-provider communication and continuity of care.

Admissibility of foreign educated personnel who seek an employment-based visa to travel to a foreign country is 
usually determined by the curriculum content of the foreign training through evaluation of examination transcripts. In the United States, foreign-trained physiotherapists currently licensed to practice in one state are not granted reciprocity and are often required to take courses before they can be licensed to practice in another state. Discrepancies in national curricula that could be construed as deficiencies place restrictions on foreigntrained physiotherapists' mobility.

In the past decades, Nigeria lost many physiotherapists to other countries due to high demand (Oyeyemi, 2001), and the liberal emigration policies of some developed countries (BHO, 2007; DCIC, 2009; USDOS, 2007) is believed to be contributory to the brain drain. While some economic benefits may accrue to the immigrant's home country through foreign exchange repatriation, it is hardly arguable that the net gain from brain drain is to the developed countries (Stillwell, 2004). Nevertheless, a top rate education is a national pride and fear of losing highly trained professionals to developed countries is not a justification for substandard training.

Higher education is still perceived as a public good, and the government are saddled with its provision. Although it is a general presumption that no nation sets out to train personnel for external use, there is a growing consideration for higher education as a business. In Australia, for example, education has been contributing substantially to the country's external trade and was the nation's ninth largest export earner (Coleman, 2003). Internationalized education could enhance the competency of Nigerian trainees and improve their global competitiveness, and it could attract students from other countries.

In transnational education, indigenous teachers are neither supplanted with foreign ones, nor are students or even teachers required to travel abroad to receive or provide any training. The challenge of international physiotherapy education is to advance the science of physiotherapy while celebrating and learning from cultural differences to best meet the need of an informed consumer. Equipping training institutions to evolve from a narrow, national perspective is a necessary step to training personnel that will provide service in this postmodern time.

Nigeria is a multi-cultural society and as an economic power in Africa, health professional education, as with education for other disciplines in this country should prepare graduates for service in the country, other parts of Africa and the world. International physiotherapy and health professional education is therefore an essential goal as Nigeria strives to become one of the first twenty (20) economic powers in the year 2020. Although physiotherapy education in Nigeria has in the past enjoyed and perhaps up till now still enjoys international status, some curriculum enhancements are needed to maintain its frontline status.

Physiotherapy training enhancements that could reposition Nigerian programmes in its leading position in the world may involve doctoral level preparatory education. The acquisition of electronic and pedagogical infrastructure, including online learning resources such as global student online discussions, ask the expert facilities, and the use of a bank of virtual patients will facilitate this. Qualified Nigerians in the diaspora could be utilized as visiting lecturers and with proper incentives may also be encouraged to return to their home country.

\section{References}

Aluwihare, A.P.R. 2005. Physician migration: donor country impact. Journal of Continuing Education 25: 15-21.

Backlay, J. 1995. In Good Hands. History of Chartered Society of Physiotherapy 1894-1994. Oxford: Butterworth Heineman.

Beerkens, E. 2003. Globalizations and higher education research. Studies in International Education 7(2): 128-148.

British Home Office (BHO). 2007. Immigrating to Britain. [Online] Available at http://www.ind.homeoffice.gov.uk/ind /en/home/coming_to_the_uk.html? [Accessed 28 November 2007].

Broadhead, R.L. and Muula A.S. 2002. Creating a medical school for Malawi; Problems and achievements. British Medical Journal 325: 384-387.

Coleman, D. 2003. Quality assurance in transnational education. Studies in International Education 7: 354-378.

Department of Citizenship and Immigration Canada (DCIC). 2009. Immigrating to Canada as a Skilled Worker [Online] Available at http://www.cic.gc.ca/english/skilled/index.html [Accessed 28 November 2009].

Harden, R.M. 2002. Developments in outcome-based education. Medical Teacher 24: 117-120.

Harden, R.M. and Hart I.R 2002. An international virtual medical school (IVIMEDS): The future for medical education? Medical Teacher 24: 261-267.

Harden, R.M. 2006. International medical education and future directions: A global perspective. Academic Medicine 81 (12): S22-S28.

Huang F. 2003. Policy and practice of the internationalization of higher education in China. Journal of Studies in International Education 7: 225-240.

Knight J. 2005. International Association of Universities (IAU). Internationalization Survey Preliminary Findings Report. Paris 2005. Available at (http://www.unesco.org /iau/internationalization/pdf/internationalization_2005.pdf. Accessed April 6, 2006. 
Koehn, P.H. and Swick M.D. 2006. Medical education for a changing world: Moving beyond cultural competence into transnational competence. Academic Medicine 81(6): 548556.

Mullan, F. 2005. The metrics of the physicians brain drain. New England Journal of Medicine 353: 1810-1818

New York Institute of Technology (NYIT). (2007). Transitional Doctor of Physical Therapy Program in Brazil [Online]. Available at http:www.nyt.edu/health_professions/programs/ [Accessed July 7, 2008].

Oyeyemi AY. 2001. Job satisfaction traits of Nigerian physiotherapists. Physiotherapy Theory and Practice 17: 257268.

Salfsky, B., Glasser M. and Ha J. 2005.Addressing issues of maldistribution of health care workers. Annals of Academy of Medicine in Singapore 34: 520-525.

Schwarz, M.R. and Wojtczak A. 2002. Global minimum essential requirements: a road towards competency-oriented medical education. Medical Teacher 24: 125-129.

Smith, S.R., Cookson J., McKendree J. and Harden R.M. 2007. Patient-centered learning-back to the future. Medical Teacher 29(1): 33-37

Squires, D. 1999. Peripatetic electronic teachers in higher education.Journal of the Association for Learning Technology 7: 52-63.
Stillwell B., Diallo K., Zurn P., Vujicic M., Adams O. and Dal Poz M.. 2004. Migration of health-care workers from developing countries: strategic approaches to its management. Bulletin of the World Health Organization 82(8): 595-510.

Teichler, U. 2003. Mutual recognition and credit transfer in Europe: Experiences and problems. Journal of Studies in International Education 7: 312-341.Touro College. 2008. Doctor of Physical Therapy Program in Israel [Online] http:www.touro.edu/grad/online /program.asp [Accessed July 7, 2008]

U.S Department of State, Bureau of Consular Affairs (USDOS). 2007. Diversity Visa Lottery Instruction [Online]. Available a t h t t p : / / t r a vel.s t a t e.g o v/ vis a /immigrants/types/type_1318.html [Accessed 24 November 2007].

World Confederation for Physical Therapy (WCPT). 2009. Position Statement-Guidelines for Physical Therapist Entry Level Education. Available a t hhtp://www.wcpt.org/print/29550 [Accessed 27 September 2009]. 